\title{
Radio Wave Propagation Experiment in Sugarcane Fire Environments
}

\author{
Douglas Letsholathebe ${ }^{1 *}$, Kgakgamatso M. Mphale1, Samuel Chimidza1, Malcolm L. Heron ${ }^{2}$ \\ ${ }^{1}$ Physics Department, University of Botswana, Gaborone, Botswana \\ ${ }^{2}$ Marine Geophysical Laboratory, James Cook University, Townsville, Australia \\ Email: *mphalekm@mopipi.ub.bw
}

Received 20 January 2016; accepted 18 July 2016; published 21 July 2016

Copyright (C) 2016 by authors and Scientific Research Publishing Inc.

This work is licensed under the Creative Commons Attribution International License (CC BY).

http://creativecommons.org/licenses/by/4.0/

c) (i) Open Access

\begin{abstract}
Large fires have an effect of suppressing Very or Ultra High Frequency (VHF/UHF) radio wave signals strength which consequently impact negatively on the efficiency of radio communications at the frequency ranges. Mobile hand-held radio operating at the frequency ranges is a major communication tool during fire suppression; therefore inefficient radio communication systems put lives of fire fighters at risk. One of the causes of signal attenuation in fire environment is plume ionization. Plume species which include graphitic carbon, alkalis and thermally excited radicals such as methyl are responsible for ionization. As atmospheric pressure ionized medium (combustion plasma), sugarcane fire has momentum transfer electron-neutral collision frequency much higher than plasma frequency, hence propagation of VHF/UHF radio waves through such a medium is predicted to suffer a significant attenuation and phase shift. Radiowave propagation measurements were carried out in a moderate intensity prescribed sugarcane fire at $151 \mathrm{MHz}$ frequency over a $590 \mathrm{~m}$ path using a radiowave interferometer. The radio wave interferometer measured signal attenuation of $0.43 \mathrm{~dB}$ through the fire with maximum temperature and flame depth of $1154 \mathrm{~K}$ and $8.7 \mathrm{~m}$, respectively.
\end{abstract}

\section{Keywords}

Canefire, Radiowave Loss, Attenuation, Thermal Ionization

\section{Introduction}

The Burdekin Delta is known for its high sugar cane (Saccharum spp.) crop yield in Australia [1]. High annual rainfall, which is over a $1000 \mathrm{~mm}$ and high soil fertility, makes it suitable for sugar cane farming. Potassium

\footnotetext{
"Corresponding author.
}

How to cite this paper: Letsholathebe, D., Mphale, K.M., Chimidza, S. and Heron, M.L. (2016) Radio Wave Propagation Experiment in Sugarcane Fire Environments. Journal of Electromagnetic Analysis and Applications, 8, 124-131. 
enriched nutrients, such as potash, are often used to supplement soil fertility in cane paddocks in order to increase crop yields. Potassium content in sugar cane may be up to $2.2 \%$ on dry weight basis. In northeast Queensland, it is a common agricultural practice to burn foliage before harvesting sugar cane [2]. The cane burning is done when weather conditions do not favor the development of very high intensity cane fires. It is for this reason that burning is normally done at dusk when atmospheric instability is low. Otherwise the cane fires, which are often large (see Figure 1), will burn out of control. In instances where cane fires get out of control, radio wave communication systems which are commonly used in fire suppression should be able to function effectively under such environment.

Sugarcane fire flame temperatures are in the range of $600^{\circ} \mathrm{C}-1000^{\circ} \mathrm{C}$ [3]. Potassium, which exists in cane foliage, is volatilized by the intense heat and drawn by convective currents into the flame where it is thermally ionized to give electrons [4]. The fires move rapidly and turbulently mix with convected surrounding air. Cool night air quenches the heat in the flame to temperatures lower than $1000^{\circ} \mathrm{C}$. Moist combustion conditions prevail in the cane fires. The moist conditions and up draughts promote the release of potassium into the flame as hydroxide (KOH) and $\mathrm{K}$ atoms [5] [6]. Potassium contributes significantly to ionization in the fires provided flame temperatures are higher than $900^{\circ} \mathrm{C}$.

The paper reports on radio wave propagation measurements carried out in a prescribed agricultural fire in a sugarcane field at Australian Tropical Agriculture College (ATAC) in Clare, Lower Burdekin. The measurements were performed using a radio wave interferometer, an instrument specifically designed to measure attenuation or phase change of a radio wave signal after passing through a fire plume [7]. Phase change measurement involves running a reference signal from a transmitter to receiver circuits for phase comparison. The reference signal is phase coherent with a signal from the transmitter unit before the latter traverses a cane fire. However in this experiment, phase measurements were not possible because the sides of the sugarcane paddock were very long to consider running a reference signal cable.

\section{Theoretical Consideration}

If a plane polarized electromagnetic wave is considered to travel in the positive $x$-direction, its signal strength $(E)$ at any given time can be given as;

$$
E=E_{0} \mathrm{e}^{i(\omega \cdot t-\gamma \cdot x)}
$$

where $\gamma$ is propagation constant, $\omega$ is cyclic propagation frequency $(=2 \pi f)$ and $E_{0}$ is initial electric field strength of the radio signal. According to Akthar [8], propagation constant $(\gamma)$ is related to attenuation $(\alpha)$ and shift $(\beta)$ coefficients in a medium by the relation; $\gamma=\alpha+i(\beta)$. Equation (1) can therefore be expressed as:

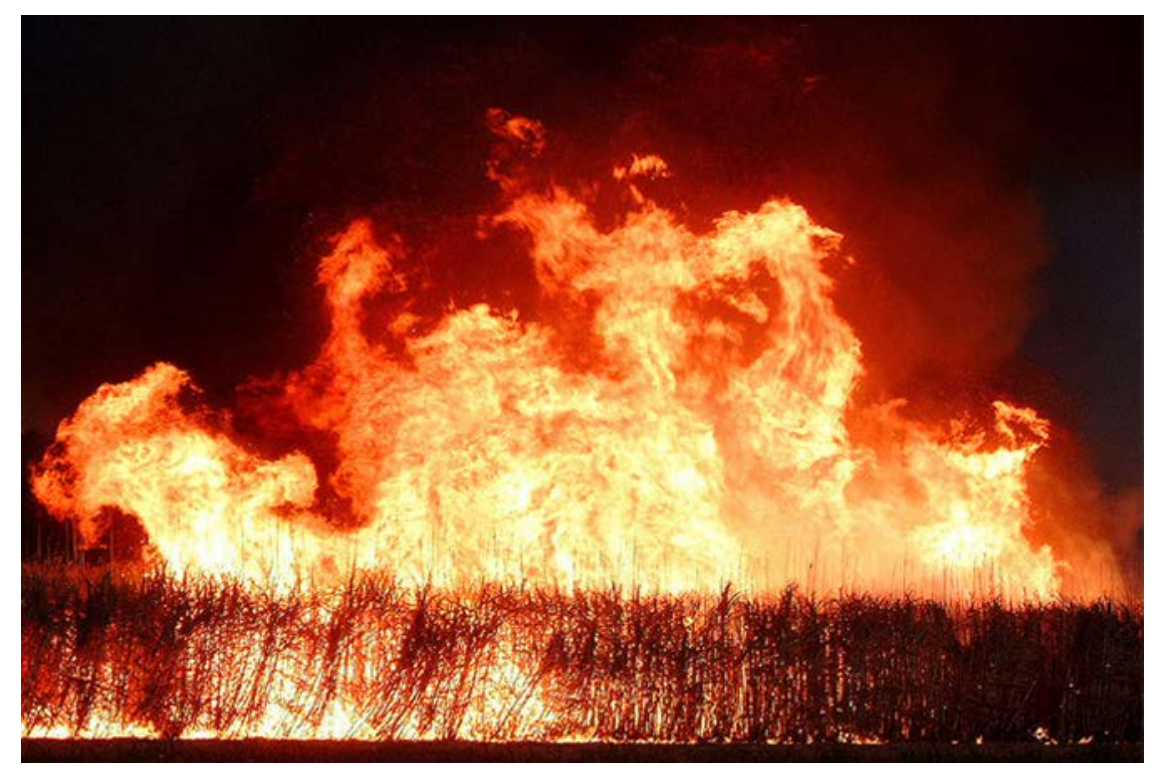

Figure 1. Large sugarcane fire (Photo: John Maddocks, 2003). 


$$
E=E_{0} \mathrm{e}^{-\beta z}\{\cos (\omega t-\alpha x)\}
$$

Classical electromagnetic wave theory predicts significant loss of signal amplitude and a change of phase when an electromagnetic wave traverses a lossy medium such as a sugarcane fire plume. The induced phase shift and loss in signal are due to electric dielectric permittivity which is not equal to unity (1). Dielectric permittivity of vacuum is equal to unity. The two effects in a lossy medium are measurable and can be related to those in free space. Amplitude of a radio signal that propagates through a sugarcane fire is attenuated and is given by;

$$
E_{f}=E_{0} \mathrm{e}^{-\alpha_{f} x}
$$

Without a canefire intercepting the propagation path, the amplitude of the signal that traversed air is not attenuated, and is given by;

$$
E_{a}=E_{0}
$$

as attenuation coefficient $\left(\alpha_{f}\right)$ is zero (0). Attenuation (Attn) of the signal that traverses canefire expressed in $\mathrm{dB}$ is;

$$
\begin{aligned}
& \operatorname{Attn}(\mathrm{dB})=10 \log _{10}\left\{\left(\frac{E_{a}}{E_{f}}\right)^{2}\right\} \\
& \operatorname{Attn}(\mathrm{dB})=10 \log _{10}\left\{\mathrm{e}^{2 \alpha_{f} x}\right\}
\end{aligned}
$$

\section{Materials and Methods}

\subsection{The Study Area}

The sugarcane paddock where the prescribed burn was carried out was at the Burdekin Agricultural College in Clare. Clare is $90 \mathrm{~km}$ south of Townsville in the Burdekin Delta (19 $35^{\prime} \mathrm{S}$ and $147^{\circ} 24^{\prime} \mathrm{E}$ ) (Figure 2). It is $40 \mathrm{~km}$ from Ayr and $30 \mathrm{~km}$ from Home Hill. The paddock is one of the 400ha of sugar cane paddocks owned by the Agricultural College. The climate in the area is monsoonal with hot wet summers and warm dry winters. Average rainfall in the region is $1032 \mathrm{~mm}$. The soils are fertile alluvial with variable layering [9]. This fertile soils and the high rainfall in the regions makes it suitable for sugar cane farming.

\subsection{Fuel Characteristics}

The sugarcane considered for harvesting was a year old (mature) and nearly $6 \mathrm{~m}$ tall. Its leaves in the bottom 3 $\mathrm{m}$ were fully dried while those in the rest of height of straw were half dried. Separation between the cane rows

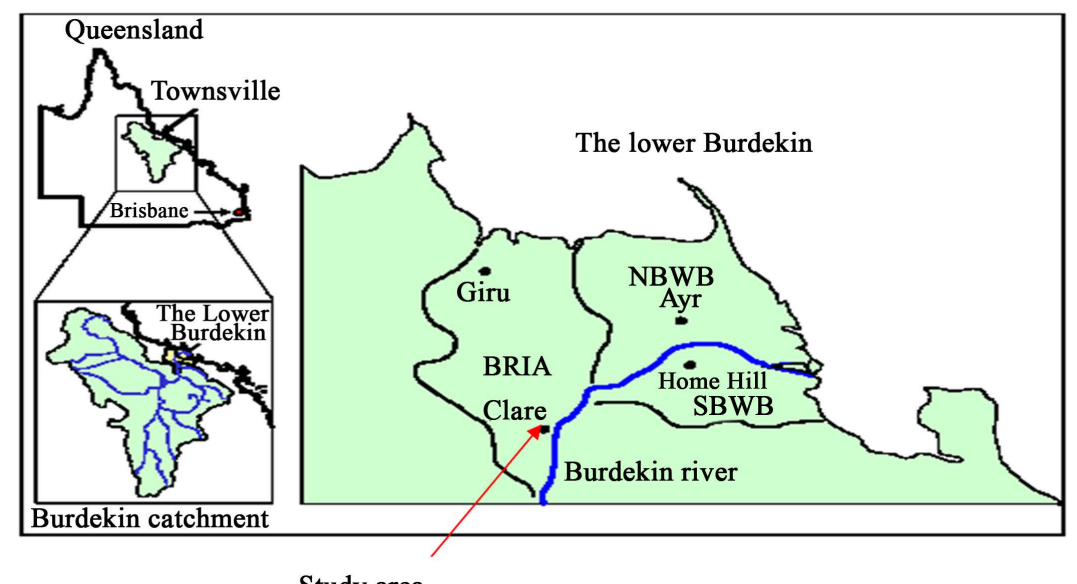

Study area

Figure 2. The location of the study area (adapted from: Charles worth et al. 2002). 
in the paddock was $1 \mathrm{~m}$. The crops were closely packed and almost impossible for one to walk across the rows. Though the cane was mature, most of it had not flowered. The length of the paddock was roughly $1000 \mathrm{~m}$ and $100 \mathrm{~m}$ wide (see Figure 3).

\subsection{Radio Wave Propagation Measurements}

Receiver ( $\mathbf{R x})$ and transmitters ( $\mathbf{T x})$ units of a Radio Wave Interferometer were set up on adjacent sides of the sugar cane paddock (sides $\mathbf{A B}$ and $\mathbf{B C}$ in Figure 3). The distance separating the units ( $\mathbf{T x}-\mathbf{R x}$ ) was $581.5 \mathrm{~m}$. The units were set some distance away from the paddock so that they are not affected by heat from the burning sugarcane. $\mathbf{R x}$ was set $20 \mathrm{~m}$ from $A B$ such that from $B_{1}$ to the $\mathbf{R x}$ was $115 \mathrm{~m}$. $\mathbf{T x}$ was $30 \mathrm{~m}$ from $\mathrm{BC}$ such that $\mathbf{T} \mathbf{x}$ was $570 \mathrm{~m}$ from $\mathbf{B}_{2}$. The distance of $\mathbf{B e}$ to $\mathbf{B}_{\mathbf{f}}$ was $556 \mathrm{~m}$. The $\mathbf{R} \mathbf{x}$ and $\mathbf{T} \mathbf{x}$ antennas were set $3.2 \mathrm{~m}$ high from the ground facing each other to maximize the amount of signal strength received at $\mathbf{R x}$. The antennas were tuned such that the maximum strength received at $\mathbf{R x}$ was $689 \mathrm{mV}$. Signal strength readings at $\mathbf{R x}$ were then logged into $\mathrm{HOBO}^{\circledR}$ data logger for continuous monitoring.

The $\mathbf{T} \mathbf{x}$ and $\mathbf{R x}$ units were enclosed in polystyrene boxes wrapped with aluminum foil to reflect heat from cane fire. The radio wave interferometer was switched on at $6.20 \mathrm{pm}$ while the HOBO data logger was switched on at $6.24 \mathrm{pm}$ to allow the instrument to stabilize.

\subsection{Sugarcane Fire Behavior}

The sugarcane fire was ignited along the side AB (Figure 3) with liquid flame. At the time of ignition, a mild wind blew form the easterly direction. The wind forced the fire to propagate along the length of the paddock thus intercepting the propagation path (shown in Figure 3) at an angle of approximately $79^{\circ}$.

\subsection{Temperature Measurements}

A thermocouple tower of height $6.1 \mathrm{~m}$ was constructed from a steel pipe (stem) of diameter $0.15 \mathrm{~m}$. The tower was erected inside the paddock, a few meters from its edge. To the steel pipe stem, six steel pipes of diameter 20 $\mathrm{cm}$ were screwed to the stem forming "branches" at every $1.0 \mathrm{~m}$ of the stem height. Thermocouples were mounted at each branch.

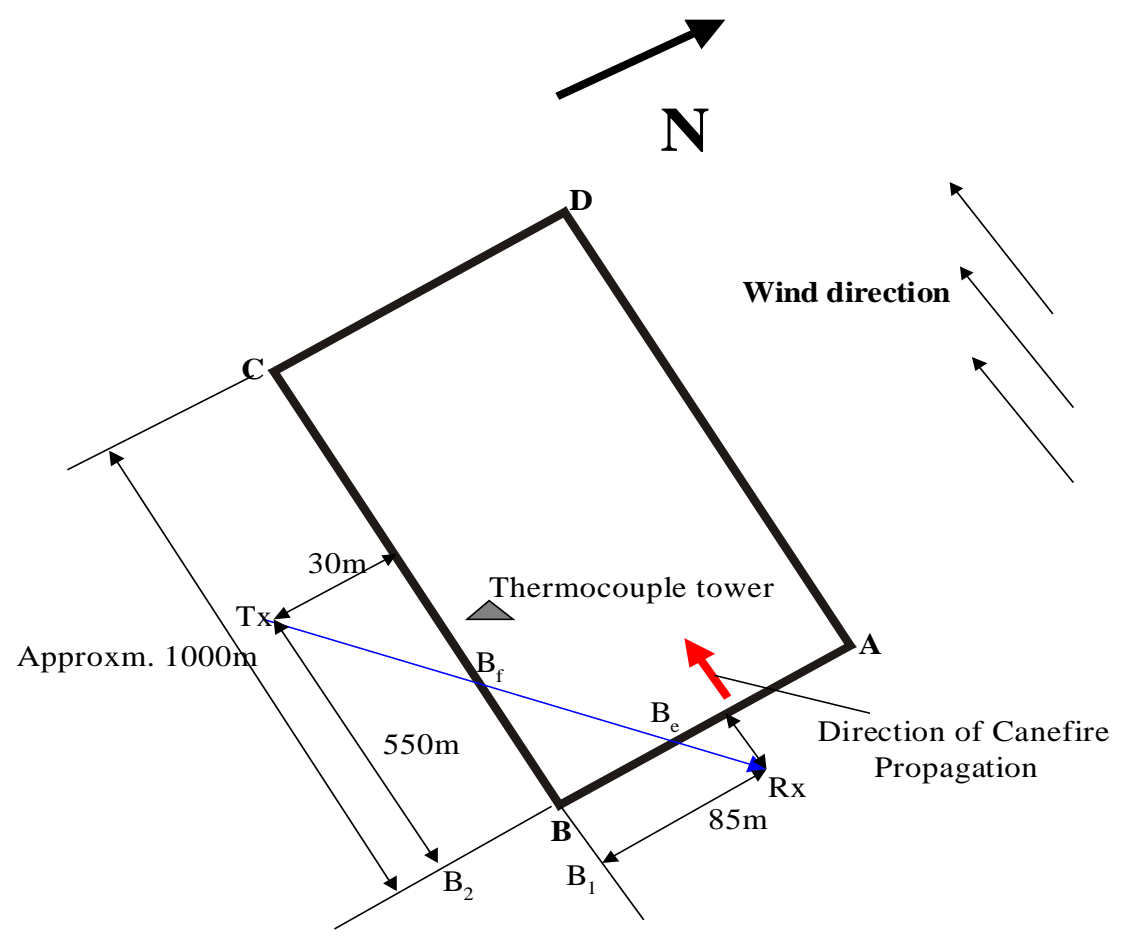

Figure 3. Set up for the transmitter and receiver units at the study site. 
The thermocouples were cut from a $100 \mathrm{~m}$ roll of double braided fiberglass insulated chromel-alumel (24-G/G) thermocouple wire $50 \mu \mathrm{m}$ in diameter. The type $\mathrm{K}$ thermocouple wires were electro-fused at one end to make perfect junctions and tested with a hot air gun and a multimeter. The thermocouples were then fixed to branches by means of muffler tape and the electro-fused junctions were left protruding $2.5 \mathrm{~cm}$ beyond the branch length into the flame. The thermocouples wires were buried in a trench $20 \mathrm{~cm}$ deep and connected to the SPECTRUM ${ }^{\circledR}$ data logger $50 \mathrm{~cm}$ away from the tower.

The thermocouples were wired to a SPECTRUM ${ }^{\circledR}$ SP 1700 - $51 \mathrm{~W}$ thermocouple data logger to read in temperatures throughout the experiment. Operational cold junction temperature of the data logger ranges from $-45^{\circ} \mathrm{C}$ to $85^{\circ} \mathrm{C}$; therefore it was necessary to protect the logger from heating beyond $85^{\circ} \mathrm{C}$ as this may invalidate the data. The data logger was dug $75 \mathrm{~cm}$ into ground and wrapped around with an insulating material (Fiberflex ${ }^{\circledR}$ ) to protect it from heat that may the produced in the grassfire. SP 1700-51w logger has the capability to read temperatures up to $1370^{\circ} \mathrm{C}$, therefore is ideal for measuring cane fire flame temperatures.

\section{Experimental Results and Discussions}

\subsection{Sugar Cane Fire Temperature}

There is a discrepancy between the actual combustion gas temperature and that measured by a bare bead thermocouple [10]. The error is mainly due to the convection and radiation heat transfer to and from thermocouple bead. The error, which could be up to $200 \mathrm{~K}$, is also attributable to bead physical characteristics such as emissivity and size [11]. However, actual cane fire temperatures could be reconstructed from thermocouple readings using heat balance equation. The discrepancy between the actual sugarcane fire and thermocouple measured temperature is given by Silvani and Morandini [11] as;

$$
T_{c g}-T_{t c}=\frac{\sigma \varepsilon_{t c}\left(1-\varepsilon_{c g}\right) T_{c g}^{4}}{h_{t c}+4 \sigma \varepsilon_{t c} T_{c g}^{3}}
$$

where $h_{c}=k N u / d_{t b}$ is heat transfer coefficient. $N u, k$ and $d_{t b}$ are Nusselt number, diffusivity and bead diameter, respectively. Diffusivity is related to the specific heat capacity $\left(C_{p}\right)$ and Prandtl number $(\operatorname{Pr})$ by the relation, $k=\mu C_{p} / P r$. For combustion gases, $\operatorname{Pr}$ is 0.71 . Following Dupuy [10], Equation (6) is solved for $T_{c g}$ which is actual flame gas temperature. The corrected flame temperatures are shown in Figure 4.

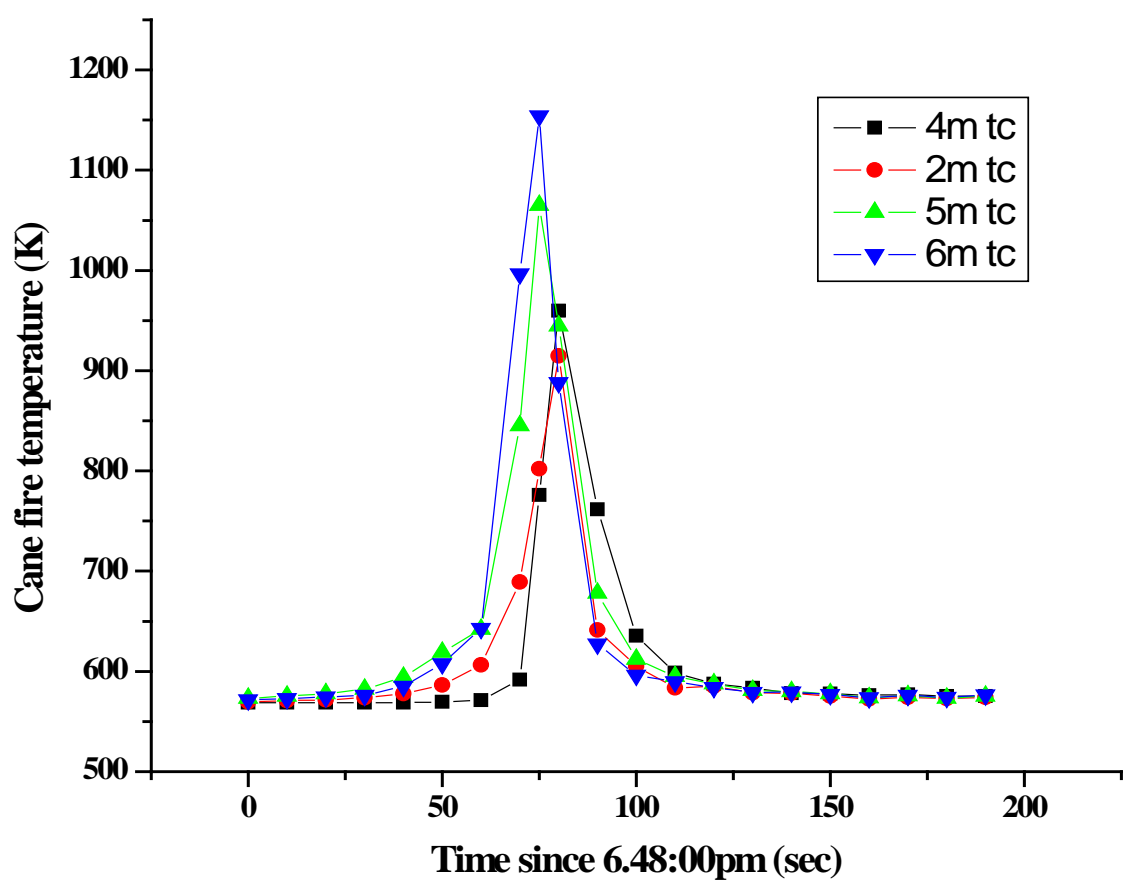

Figure 4. Sugar cane fire flame temperatures as the flame front passed the tower. 
The corrected thermocouple temperature for the sugarcane fire within the vegetation stratum was observed to increase with distance above the ground. The maximum temperature was observed at $6 \mathrm{~m}$ above the ground and was recorded to be $1154 \mathrm{~K}$. The next highest was be $1065 \mathrm{~K}$ at $5 \mathrm{~m}$ above ground. The maximum temperatures occurred at 6:49:20 pm. At other heights (2 and $4 \mathrm{~m}$ ), temperature maxima occurred $10 \mathrm{~s}$ later because the canefire was wind-blown. The maximum temperature recorded at $2 \mathrm{~m}$ above ground was $915 \mathrm{~K}$. At $4 \mathrm{~m}$, temperature was observed to be $960 \mathrm{~K}$. From the temperature measurements, it appears that the northeasterly winds that blew across the paddock affected the flame up $1 \mathrm{~m}$ deep from the sugar cane canopy.

\subsection{Sugarcane Fire Behavior}

As the sugarcane fire front raced across the paddock from the east, it left leafless and charred cane straws standing behind. The chaff was completely burnt. The flames of the sugarcane fire were observed to be about 5 - 10 $\mathrm{m}$ high. The flames were hottest near the cane canopy and its temperature decreased with the increase in height above the ground. The cane fire took 21 minutes to burn through the whole paddock.

Average Rate of Spread (ROS) for the flame which is calculated from length of the paddock and time taken by the flame to reach the side CD is $0.79 \mathrm{~m} \cdot \mathrm{s}^{-1}$. If it is assumed that flaming occurs at temperatures more than $573 \mathrm{~K}$ [13] then the resident time $\left(T_{r}\right)$ of flames above the canopy as obtained from the analysis of temperature data from SPECTRUM ${ }^{\circledR}$ SP 1700 - 51 W data logger is 11.

Noting that the head fire was rectangular, then flame depth $\left(F_{d}\right)$ is related to flame residence time $\left(T_{r}\right)$ and rate of fire spread (RoS) by the relation:

$$
F_{d}=\operatorname{RoS} \times T_{r}
$$

Equation (7) gives the average canefire flame depth of $8.69 \mathrm{~m}$.

\subsection{Attenuation of $151 \mathrm{MHz}$ Signal}

Signal reflections due to movements by team members in the first 4 mins after the logger was switched affected signal intensity. This is shown by signal dip AB in Figure 5. Figure 5 shows a 10-point adjacent averaging smoothing of real time data which is blue in color. Signal strength increased soon after that to a value of $686 \mathrm{mV}$. The ACTA fire crews moved in to set the sugar cane paddock alight at $6.36 \mathrm{pm}$. As they intercepted the propagation path the signal strength decreased to a minimum of $666 \mathrm{mV}$ which is show by a prominent dip at $\mathbf{C}$ in the

\section{MHz Signal Amplitude Vs. Time}

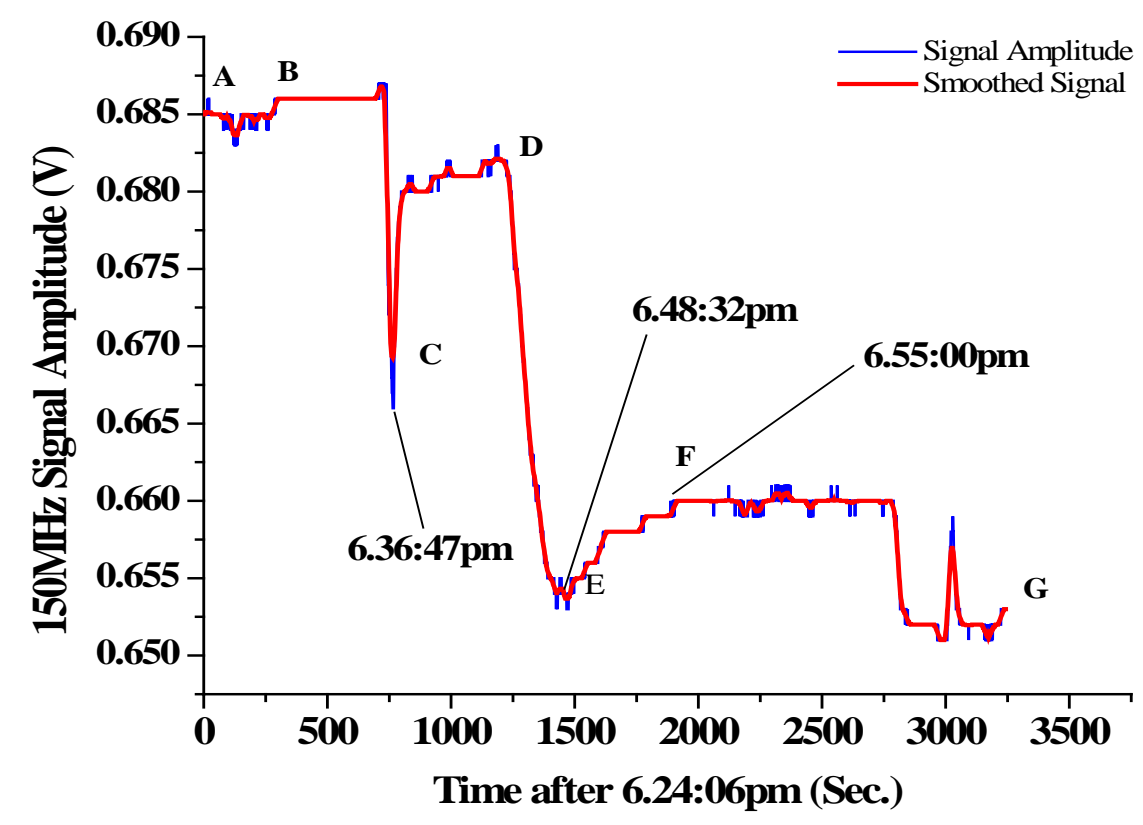

Figure 5. Signal strength response to crew and cane fire interception of the propagation path. 
same figure. As the crew moved out of the propagation path, the cane fire grew. The signal never gained its reception strength of $686 \mathrm{mV}$, but it only rose to a maximum strength of about $682 \mathrm{mV}$ (shown as $\mathbf{D}$ in Figure 5). As the fire gained strength and intercepted the propagation path the signal strength fell to a minimum of $653 \mathrm{mV}$ at 6:48:32 $\mathrm{pm}(\mathbf{E})$. Soon after the fire has passed the Propagation path, signal strength slowly rose to an average value of $660 \mathrm{mV}$ at $6.55 \mathrm{pm}$ (F in Figure 5) until the instruments were disconnected at 7:10 pm.

Using the smoothed data attenuation of the $150 \mathrm{MHz}$ signal due to the sugarcane fire flame as per Equation (5) is:

$$
\text { Maximum attenuation due to the fire }(\mathrm{dB})=20 \log _{10}\left[\frac{0.686}{0.653}\right]=0.43 \mathrm{~dB} \text {. }
$$

After the dry chaff has been consumed by the cane fire, stalks of sugar cane remained standing in the propagation path of the $150 \mathrm{MHz}$ signal. The carbon covered stalks together with the hot air in the environment affected the signals markedly. Before the fire, the stalks are there with leaves and have the same water/sap content but do not have the carbon coating. As leaves do not attenuate radio signals at the frequency, carbon covered stalks may be the main cause of attenuation after the fire. The attenuation induced on the signal by the stocks was observed to be:

$$
\text { Attenuation due hot surface and carbon stocks }(\mathrm{dB})=20 \log _{10}\left[\frac{0.686}{0.660}\right]=0.34 \mathrm{~dB} \text {. }
$$

\section{Conclusions}

The sugarcane fire investigated had a front which was $8.7 \mathrm{~m}$ deep. The weather condition during the experiment was characterized by strong up draughts which cooled the flame intensity to maximum temperatures of $1150 \mathrm{~K}$ at the cane canopy. The temperature trend in the fuel stratum was such that it increased with height. Cane stratum temperature rose from maximum of $915 \mathrm{~K}$ at $2 \mathrm{~m}$ to a maximum of $1154 \mathrm{~K}$ at $6 \mathrm{~m}$ above the ground surface. The rate of spread for the cane fire was approximately $0.79 \mathrm{~m} \cdot \mathrm{s}^{-1}$.

At $151 \mathrm{MHz}$, radio waves were slightly affected by an $8.7 \mathrm{~m}$ thick cane fire to a maximum signal loss of 0.43 $\mathrm{dB}$. The loss in signal intensity was comparable to propagation over carbon coated stalks which registered a loss of $0.34 \mathrm{~dB}$. Considering the magnitude of attenuation, vhf radio waves were not severely impaired by the sugarcane fire; however, signal attenuation is a factor of type of modulation. Very large fires may affect the signal significantly.

\section{Acknowledgements}

We would like to gratefully acknowledge Staff Development Office of the University of Botswana for the financial support for this work. The work was partly supported by Emergency Management Australia under project no. 60/2001.

\section{References}

[1] Shannon, E.L. and Raine, S.R. (1996) Improving the Irrigation Efficiency of Burdekin Canegrowers. Proceedings of the 8th Australian Agronomy Conference, Australian Society of Agronomy, Toowoomba, 502-506.

[2] Ayer, G. (2005) Air Pollution and Climate Change: Has air Pollution Suppressed Rainfall over Australia. Clean Air and Environmental Quality, 39, 51-57.

[3] Meyer, M., Mueller, J.F., Beer, T., Marney, D. and Bradbury, G. (2004) Field and Laboratory Based Emission Factors for PCDD/PCDF/PCB from Sugarcane Fires. Organohalogen Compounds, 66, 928-934.

[4] Raison, R.J., Khaina, P.K. and Woods, P. (1985) Mechanisms of Element Transfer to the Atmosphere during Vegetation Burning. Canadian Journal of Forest Research, 15, 132-140. http://dx.doi.org/10.1139/x85-022

[5] Westberg, H.M., Bystrom, M. and Lecker, B. (2003) Distribution of Potassium, Chlorine and Sulphur between Solid and Vapour Phases during Combustion of Wood and Coal. Energy and Fuels, 17, 18-28. http://dx.doi.org/10.1021/ef020060l

[6] Okuno, T., Sonoyama, N., Hayashi, J., Li, C., Sathe, C. and Chiba, T. (2005) Primary Release of Alkali and Alkaline Earth Metallic Species during Pyrolysis of Pulverized Biomass. Energy and Fuels, 19, 2164-2171. http://dx.doi.org/10.1021/ef050002a 
[7] Mphale, K.M. (2008) Radio Wave Propagation and Prediction in Bushfires. Ph.D. Thesis, James Cook University, Townsville.

[8] Akhtar, K., Scharer, E.J., Tysk, S.M. and Kho, E. (2003) Plasma Interferometry at High Pressures. Review of Scientific Instruments, 74, 996-1001. http://dx.doi.org/10.1063/1.1533104

[9] Charlesworth, P.B. and Bristow, K.L. (2002) Sustainable Management of the Burdekin Groundwater System. Milestone Report to the National Program for Irrigation Research and Development.

[10] Dupuy, J.L., Marechal, J. and Morvan, D. (2003) Fires from a Cylindrical Forest Fuel Burner: Combustion Dynamics and Flame Properties. Combustion and Flame, 135, 65-76. http://dx.doi.org/10.1016/S0010-2180(03)00147-0

[11] Brohez, S., Delvosalle, C. and Marlair, G. (2004) A Two Thermocouples Probe for Radiation Correction of Measured Temperatures in Compartment Fires. Fire Safety Journal, 39, 399-411. http://dx.doi.org/10.1016/j.firesaf.2004.03.002

[12] Silvani, X. and Morandini, F. (2009) Fire Spread Experiments in the Field: Temperature and Heat Fluxes Measurements. Fire Safety Journal, 44, 279-285. http://dx.doi.org/10.1016/j.firesaf.2008.06.004

[13] Stott, P. (2000) Combustion in Tropical Biomass Fires: A Critical Review. Progress in Physical Geography, 24, 355377. http://dx.doi.org/10.1177/030913330002400303

\section{Submit or recommend next manuscript to SCIRP and we will provide best service for you:}

Accepting pre-submission inquiries through Email, Facebook, LinkedIn, Twitter, etc.

A wide selection of journals (inclusive of 9 subjects, more than 200 journals)

Providing 24-hour high-quality service

User-friendly online submission system

Fair and swift peer-review system

Efficient typesetting and proofreading procedure

Display of the result of downloads and visits, as well as the number of cited articles

Maximum dissemination of your research work

Submit your manuscript at: http://papersubmission.scirp.org/ 